NBER WORKING PAPER SERIES

\title{
PAY TRANSPARENCY AND THE GENDER GAP
}

\author{
Michael Baker \\ Yosh Halberstam \\ Kory Kroft \\ Alexandre Mas \\ Derek Messacar \\ Working Paper 25834 \\ http://www.nber.org/papers/w25834 \\ NATIONAL BUREAU OF ECONOMIC RESEARCH \\ 1050 Massachusetts Avenue \\ Cambridge, MA 02138 \\ May 2019, Revised November 2019
}

We thank Sarah Kaplan, Matthew Notowidigdo, and colleagues at Princeton and the University of Toronto, and seminar participants at Memorial University of Newfoundland, the NBER Summer Institute, UC-Davis, and the University of Waterloo for helpful comments as well as Teresa Omiecinski and Donna Towns at Statistics Canada for their assistance with the data. Paul Han, Jared Grogan, Chester Madrazo and Ruizhi Zhu provided excellent research assistance. We gratefully acknowledge financial support from the Institute for Gender and the Economy (GATE) at the Rotman School of Management. Baker gratefully acknowledges the research support of a Canada Research Chair at the University of Toronto. The views and opinions expressed herein are those of the authors and do not necessarily reflect the views of Statistics Canada, the Government of Canada, or the National Bureau of Economic Research.

NBER working papers are circulated for discussion and comment purposes. They have not been peer-reviewed or been subject to the review by the NBER Board of Directors that accompanies official NBER publications.

(C) 2019 by Michael Baker, Yosh Halberstam, Kory Kroft, Alexandre Mas, and Derek Messacar. All rights reserved. Short sections of text, not to exceed two paragraphs, may be quoted without explicit permission provided that full credit, including $\odot$ notice, is given to the source. 
Pay Transparency and the Gender Gap

Michael Baker, Yosh Halberstam, Kory Kroft, Alexandre Mas, and Derek Messacar

NBER Working Paper No. 25834

May 2019, Revised November 2019

JEL No. J0,J3,J31

\begin{abstract}
$\underline{\text { ABSTRACT }}$
We examine the impact of public sector salary disclosure laws on university faculty salaries in Canada. The laws, which enable public access to the salaries of individual faculty if they exceed specified thresholds, were introduced in different provinces at different times. Using detailed administrative data covering the majority of faculty in Canada, and an event-study research design that exploits within-province variation in exposure to the policy across institutions and academic departments, we find robust evidence that that the laws reduced the gender pay gap between men and women by approximately 30 percent. There is suggestive evidence that higher female salaries contributed to the narrowing of the gender gap. The reduction in the gender gap is primarily in universities where faculty are unionized.

Michael Baker

Department of Economics

University of Toronto

150 St. George Street

Toronto, ON M5S 3G7

CANADA

and NBER

baker@chass.utoronto.ca

Yosh Halberstam

Department of Economics

University of Toronto

150 St. George Street

Toronto, ON M5S 3G7

Canada

yosh.halberstam@utoronto.ca

Kory Kroft

Department of Economics

University of Toronto

150 St. George Street

Toronto, ON M5S 3G7

CANADA

and NBER

kory.kroft@utoronto.ca

Alexandre Mas

Industrial Relations Section

Simpson International Building

Princeton University

Princeton, NJ 08544

and NBER

amas@princeton.edu

Derek Messacar

Social Analysis and Modelling Division

Statistics Canada

100 Tunney's Pasture Driveway

Ottawa, Ontario, K1A 0T6

Canada

and Memorial University of Newfoundland

derek.messacar@canada.ca
\end{abstract}




\section{Introduction}

One of the most persistent and salient features of labor markets around the world is that women earn less than men. For example, in the United States, a woman earns roughly 77 dollars for every 100 dollars earned by a man (Goldin, 2014). A hypothesis gaining traction among academic researchers and policymakers is that the gender gap in earnings persists, in part, because it is hidden (Trotter et al., 2017). This belief is expressed in a series of policy reforms that mandate the disclosure of salaries broken down by gender. ${ }^{2}$ In 2016, President Obama of the United States issued an Executive Order expanding pay disclosure requirements for employers with more than 100 employees; however, this order was subsequently rolled back by President Trump. ${ }^{3}$ There have also been calls in the private sector for more transparency about pay differences between male and female workers. Technology firms, for example, are facing growing public pressure to disclose salaries by gender. ${ }^{4}$

Outside of the United States, transparency laws are increasingly considered as a policy to reduce the gender gap. Denmark introduced legislation in 2006 requiring large firms to report wage statistics by gender (Bennedsen et al., 2019). Starting in 2017, firms in the United Kingdom with more than 250 employees are required to report salaries and bonuses by gender. ${ }^{5}$ Similar reforms are underway in Australia, France, and Germany. In Canada, the recent Pay Transparency Act introduced in Ontario requires: (a) all publicly advertised job postings to include a salary range, (b) prohibits employers from asking about past compensation, and (c) mandates that employers report gender earning gaps to the Province. ${ }^{6}$

\footnotetext{
2 Throughout we will use the terms "pay transparency" and "salary disclosure" interchangeably.

${ }^{3}$ See http://wapo.st/2vMvIph?tid=sS tw\&utm term=.a21256120472.

${ }^{4}$ See https://www.bloomberg.com/news/articles/2017-04-13/tech-companies-tout-gender-pay-equity-but-balk-attransparency but also https://www.nytimes.com/2019/03/07/opinion/google-pay-gap.html

${ }^{5}$ See http://www.legislation.gov.uk/uksi/2017/172/pdfs/uksi 20170172 en.pdf

${ }^{6}$ This law was set to come into effect on January 1, 2019, but its implementation is pending further consultation with employers.
} 
Despite the proliferation of pay transparency legislation as a tool to reduce pay inequalities and the gender gap, there is limited research that sheds light on its effectiveness. The objective of this paper is to provide new evidence on whether pay transparency laws, as implemented by policymakers, reduce the gender pay gap.

We examine the impact of the (staggered) introduction of pay disclosure laws in Canada on university faculty salaries. The laws, which cover public sector workers and apply to most university faculty in Canada, enable public access to the salaries of individual faculty if they exceed specified thresholds. In 1996, British Columbia, Manitoba and Ontario were the first to introduce disclosure laws that required universities to report the salaries of each employee earning in excess of $\$ 50,000, \$ 50,000$ and $\$ 100,000$, respectively. Disclosure laws in other provinces have passed more recently, and currently only four of the ten provinces lack explicit legal means to publicize university faculty salaries.

To evaluate the effect of these laws on faculty salaries, we leverage restricted-use Statistics Canada data, which contain the salaries, demographic characteristics and job-related variables of full-time academic employees at Canadian universities since 1970. These data, which have close to universal coverage of full-time faculty at Canadian universities, allow us to discern faculty with salaries that meet the disclosure requirement within their province. Additionally, because the data contain an indicator for the academic unit of each individual faculty member, we are able to observe faculty with co-workers whose salaries are disclosed. This is one of the few datasets in Canada that jointly provides information on earnings and demographic characteristics of both employees and their co-workers for a comprehensive set of employers within a sector.

Our research design uses variation in university departments within provinces. Because salaries were only disclosed if they exceeded a legally determined threshold, lower paying departments, in contrast to higher paying departments, were not affected by the laws. 
Specifically, we define academic units where the salary of at least one faculty member was disclosed as "exposed" to treatment, providing a source of variation in exposure to the law within province. Thus, we can define treatment and control groups at the level of an academic unit and control for time-varying trends at the province level in a flexible manner.

We find that, on average, transparency laws significantly reduced the male-female salary gap. In particular, transparency laws led to a statistically significant 2 percentage point reduction in the gender gap, controlling for a rich set of employer and individual characteristics. This effect represents a 30 percent reduction in the gender gap, off of a base of 6-7 percent, which was the gender gap that prevailed at the time of the first pay transparency reforms that we study. In addition, this estimate is robust to using variation in level of exposure at the departmental level and department by rank level for identification. It is also robust to controlling for individual fixed effects and time-varying individual-level observables, such as whether the individual has senior administrative responsibilities. We also find that the effect of salary disclosure laws on the gender pay gap is more pronounced in unionized workplaces.

A natural question to ask is whether our results are driven by an increase in female salaries, a decrease in male salaries, or both. Using within-province variation in exposure to the transparency laws across departments, the point estimates suggest that the gender gap declined primarily as a result of higher female salaries. The magnitude of the increase in female wages, however, is imprecisely estimated in models that include individual fixed effects. ${ }^{7}$

The university sector is a good setting for studying the impact of transparency laws on the gender gap for several reasons. First, a gender gap is pervasive at all academic ranks and across all academic institutions in Canada over the period we study. ${ }^{8}$ Second, there is consensus

\footnotetext{
${ }^{7}$ There is some evidence of a reduction in male salaries, particularly in models where the comparison group is defined as workers in the same department and same rank and when individual fixed effects are included.

${ }^{8}$ For example, previous research has shown that only 36 percent of associate professors and 22 percent of full professors are women, despite the fact that women account for nearly half of all assistant professors (Council of
} 
on the "output" of academic faculty_classes taught, research publications, administrative service - and all of which are relatively easy to observe. Therefore, these criteria could provide convincing and well-cited arguments that could be used for salary redress by the information revealed by a disclosure law. Third, the well-established and widely adopted divisions of faculty by department and rank enable a precise definition of reference groups. Fourth, given the determination of salaries in the Canadian academic sector, in which faculty are paid on a 12month rather than 9-month basis, earnings differentials reflect wage differentials rather than differences in hours worked. ${ }^{9}$ Finally, the ease of accessing the information revealed by some of the disclosure laws we study depends on access to the Internet, and universities have been at the forefront of providing Internet access to their employees over the study period.

The rest of the paper is organized as follows: Section 2 summarizes the relevant literature. Section 3 provides an overview of public sector disclosure laws in Canada and discusses the mechanisms by which transparency laws might affect the gender wage gap. Section 4 describes the data. Section 5 the event-study specification. Section 6 contains the empirical analysis of pay transparency laws. Section 7 concludes.

\section{Literature}

Our paper contributes to a growing literature on pay transparency. Some studies have examined the effects of transparency on wages. For example, Gomez and Wald (2010) evaluate the impact of pay disclosure in the province of Ontario. They find that salaries of university presidents in the province increased relative to the average public sector salary, and also led to

\footnotetext{
Canadian Academies, 2012). Additionally, when comparing the salaries of men and women at universities, men's salaries are higher at all faculty ranks, controlling for experience (Boyd et al., 2012).

${ }^{9}$ Base salary is the salary measure used throughout this study, as this outcome is observed for all institutions and years. Thus, differences in pay between men and women that may arise endogenously, such as summer teaching, overload teaching, paid administrative roles, bonuses, or unpaid leave (including maternity or parental leave) are excluded. This issue is discussed further, below.
} 
higher growth in average professorial salaries in Ontario relative to other provinces. ${ }^{10}$ Similarly, Mas (2017) considers the effects of a law change in California that mandated online disclosure of municipal salaries and finds compression in salaries.

Most recently, Bennedsen et al. (2019) examine the impact of a law in Denmark that required firms with more than 35 employees to provide salary statistics by gender to an employee representative. ${ }^{11}$ The data are reported for groups that are large enough to protect the anonymity of individuals. ${ }^{12}$ Using a difference-in-differences design that compares firms with 35-50 employees to firms with 20-34 employees, the authors report that the disclosure law led to a reduction in the gender wage gap in treated firms primarily due to a slowing of males' wage growth. Compared to this study, in our setting, all salaries above a specified threshold are not anonymized and are individually disclosed., and accessible to the public. Likewise, Bennedsen et al. (2019) focus on private sector workers, whereas we study public sector workers..

Several studies have examined the impacts of pay transparency on other labor market outcomes. Cullen and Perez-Truglia (2018a) conducted a field experiment at a large corporation that revealed salaries of peers and managers. They find that a higher perceived peer salary lowers effort, output and retention, but a higher perceived manager salary increases these outcomes. Relatedly, Breza, Kaur and Shamdasani (2018) find that the ability of Indian manufacturing workers to learn about their peers' salaries led to lower productivity. Cullen and Pakzad-Hurson (2019) develop a dynamic bargaining model and test the equilibrium predictions regarding the introduction of pay transparency using data from an online labor market. They find

\footnotetext{
${ }^{10}$ The latter conclusion is based on a difference in differences analysis using 1991, 1996 and 2001 census data.

11 There was also an alternative choice available to employers which permitted them to replace the wage statistics broken down by gender with an internal report on equal pay.

12 Anonymity is preserved by restricting disclosure to 6-digit occupation codes that have at least 10 employees of each gender at the firm level.
} 
that higher transparency lowers wages on average, but leads to less wage dispersion across workers.

Some studies examine the connection between pay transparency and well-being. Card et al. (2012) use a randomized information experiment to show that pay transparency reduced the well-being of university faculty in departments where they earned below median pay in California. At the same time, Perez-Truglia (2019) finds a reduction in well-being following a reform in Norway that made the entire population's tax records publicly accessible online. Finally, Kim (2015) investigates the effect of US state-level laws that ban pay secrecy; that is, employer-level prohibitions on employees sharing salary information. Using a difference-indifferences design, the author reports that in states with a law prohibiting pay secrecy, the wages of college-educated females are higher leading to a lower gender pay gap.

\section{Background}

As noted in the Introduction, the first public sector salary disclosure laws were passed in 1996 in the provinces of British Columbia, Manitoba and Ontario. In each case, the government mandated disclosure of all university salaries exceeding a certain threshold $-\$ 50,000$ in British Columbia, $\$ 50,000$ in Manitoba, and \$100,000 in Ontario.

In Table 1, we outline the timing, disclosure thresholds and coverage of university faculty of the disclosure laws and legislation in provinces providing access to public salaries. ${ }^{13} \mathrm{~A}$ number of additional features of these laws are noteworthy. First, most provinces with a salary disclosure law publish the salary data online. ${ }^{14}$ The first publication of salaries online by the

\footnotetext{
${ }^{13}$ The laws covering salary disclosure in Saskatchewan are targeted at employees in crown corporations and have not been expanded to include other public employees, such as university faculty. However, the pressure of having some salaries disclosed in this province is leading the University of Saskatchewan to undertake its own transparency initiative. See https://thestarphoenix.com/news/local-news/u-of-s-online-salary-disclosure-a-step-in-the-rightdirection-expert accessed March 6, 2019

${ }^{14}$ For example, see Ontario's salary disclosure here: https://www.ontario.ca/page/public-sector-salary-disclosure.
} 
governments of Ontario, Nova Scotia, Alberta, and Newfoundland and Labrador was directly

followed by news coverage in the media with wide dissemination. However, in other provinces, disclosure laws do not require the province to make these data accessible online. In British Columbia, online access to faculty salaries was made possible in 2008 , only after a freedom of information request by journalists from the Vancouver Sun. The provincial newspaper maintained an online, searchable data bank of public sector salaries from 2008 to 2015, including faculty salaries.

Second, the initial reporting threshold for disclosure has remained fixed throughout time in most provinces but has been adjusted for inflation in others. For example, in Alberta, several years following legislation on salary disclosure for government employees, a separate act that applied more broadly to the public sector, including university faculty, was passed in 2012 with a threshold of $\$ 125,000$ adjusted annually to Alberta’s Consumer Price Index.

Finally, in some provinces, legislation affecting salary disclosure was passed prior to the legislation cited in the Table 1, but did not require public disclosure of university faculty whom we study. For example, preceding the legislation in Ontario, the salaries of government employees earning in excess of $\$ 40,000$ were published in the Public Accounts. This disclosure, however, did not cover university faculty and access was limited as it required obtaining a hard copy of the Public Accounts document. ${ }^{15}$

To the best of our knowledge, these laws only imposed transparency and were not passed in conjunction with other reforms that would affect the gender salary gap in universities.

\footnotetext{
${ }^{15}$ Starting in 1996 the Financial Information Act was in force in British Columbia which requires public bodies to prepare a statement documenting the salaries of employees making $\$ 75,000$ or more (threshold starting in 2002). We are unable to uncover any evidence that these statements were ever made public. Since 1996, public employees earning \$25,000 or more in Nova Scotia are published in the Public Accounts, but university faculty are excluded. New Brunswick has a similar requirement starting in 2008 , excluding university faculty and with a $\$ 60,000$ threshold.
} 
Moreover, our empirical analysis controls very flexibly for any time-varying shocks at the province level since we exploit variation in the salary thresholds within provinces.

Why might pay transparency affect the gender pay gap? One effect of the provision of information on gender-based salary disparities within an organization is that it may lead individuals to privately demand higher pay from their employer. The case of Lilly Ledbetter is illustrative of this mechanism. Ledbetter, a supervisor at Goodyear Tire, an American manufacturing company, was unaware that her male counterparts, in similar positions, were being paid more than she was. Revelation of this fact through an anonymous letter led her to file an employment discrimination lawsuit against her employer. This case proceeded all the way to the US Supreme Court, and subsequently led to the Lilly Ledbetter Fair Pay Act of 2009, which eased the burden of filing a discrimination lawsuit. ${ }^{16}$

The Ledbetter case emphasizes individual action by employees. It is also possible that broad salary disclosure reduces the gender pay gap as a result of an institutional response to wider public attention to pay disparities. In particular, organizations may take institutional action to make salary adjustments, in part to maintain public relations. For example, Mas (2017) finds that the disclosure of City Manager salaries in California led to a reduction in average salaries, which is interpreted as an institutional response to public outcry over high levels of compensation.

However, it is also possible that the gender wage gap is unaffected by transparency laws, or perhaps, as a result, even further widens. For example, if there is taste-based discrimination or if the gender wage gap is due to monopsony, there may not be any impact of transparency. Similarly, learning about co-workers' wages might reveal something about the nature of firmspecific rents, and if men and women use this information in a symmetric fashion in bargaining,

\footnotetext{
${ }^{16} \mathrm{See}$ https://www.congress.gov/bill/111th-congress/senate-bill/181
} 
one should not expect to see any impact on the gender pay gap. ${ }^{17}$ However, if men, but not women, use the information in bargaining, pay transparency could exacerbate the gap. ${ }^{18}$

\section{Data}

Our main estimates are based on an analysis of data from the Statistics Canada's University and College Academic Staff System (UCASS), for the years 1989 through $2017 .{ }^{19}$ This is an annual nationally-representative survey that collects data on full-time teaching staff at degree-granting Canadian universities and their affiliated colleges, as of October 1 of each year. The survey includes all teachers within faculties, academic staff in teaching hospitals, visiting academic staff, and research staff who have academic rank and salary similar to teaching staff, for all those whose term of appointment is not less than twelve months. It excludes administrative and support staff, librarians, and research and teaching assistants.

UCASS is administered directly to institutions and participation is mandatory. The unit of observation in the data is the individual but the survey unit is the institution, and information on the socio-economic characteristics of staff_-including pay_are obtained directly from payroll records. Statistics Canada works closely with institutions to maintain consistent reporting each year and to ensure the data are comparable across institutions. Individuals are assigned (anonymized) internal identification numbers so they can be followed over time within institutions, but not across institutions.

A limitation of this dataset is that it was discontinued from 2011 to 2015 . During this period, data were collected independently by participating institutions in association with the

\footnotetext{
${ }^{17}$ As Cullen and Pakzad-Hurson (2019) show however, this depends crucially on outside options. If women start out with lower outside options than men, then transparency could close the gap - even if men and women use the information in the same way.

${ }^{18}$ Leibbrandt and List (2014) present evidence that in some circumstances, men are more likely to negotiate wages than women.

${ }^{19}$ In the appendix we present results using data back until 1982.
} 
National Vice President's Academic Council leading to the construction of the National Faculty Data Pool (NFPD). The goal of the NFPD was to emulate the UCASS as closely as possible, for longitudinal consistency. Through a recent collaborative effort between Statistics Canada and the university consortium, the NFDP has been integrated with UCASS to fill in the missing years.

The NFDP has two limitations that are important to note. First, participation in the survey was voluntary. Between 2010 and 2012, the sample size decreased from approximately 35,450 workers to 27,000, and the number of institutions observed decreased from 113 to 56 . The loss of institutions is proportionately larger, as the withdrawal of a given university from the survey will also lead to the loss of all of its (small) satellite colleges. Second, for confidentiality reasons or ease of reporting, several institutions did not maintain consistent reporting of their employees' personal identifiers moving from UCASS to the NFDP in 2011 and/or back to UCASS in 2016. To overcome this issue, we match on observables to generate longitudinally-consistent identifiers for institutions where a break is observed. This is done by matching within institutions and departments based on year of birth, gender, year appointed to the institution, and year of highest degree. An assessment of the matching procedure for institutions and years where no break occurred, such that we can confirm whether the match was correct, indicates that the success rate exceeds 99 percent.

The following sample restrictions are imposed throughout this analysis. Individuals are included only if they hold appointments at the rank of assistant, associate or full professor; they are not employed in a faculty of medicine or dentistry; and they are assigned to a specific department. We make these restrictions since we have a clearer understanding of salary determination for the faculty that are included. For example, salary determination in medicine and dentistry may be affected by activities beyond research and teaching, including medical practice. We restrict to faculty with a non-missing department since our empirical specification below requires assigning a peer group based on department, and this is not possible for those not 
assigned to a department. ${ }^{20}$ Lastly, the analysis sample is restricted to institutions that are observed in the 2012 wave of the NFDP and that finalized their data with or submitted back information to Statistics Canada. This restriction on institutions is made to balance the panel around the years that the survey was discontinued.

Throughout the analysis, base salary is used as the earnings measure of interest. This measure effectively comprises the annual (12 month) rate of pay contractually negotiated and agreed upon between the employee and employer. It excludes various factors that may influence pay which may be determined endogenously, such as unpaid leave (including maternity or parental leave) and stipend pay for senior administrative duties. It also excludes income paid out of research grants and other external funding sources. ${ }^{21}$

Although the data set contains a variable for actual salary, base salary measure is used for several reasons. First, actual salary is not observed for all the relevant years. Second, Statistics Canada has worked closely with respondents to obtain a measure of base salary that is comparable across institutions and over time. Lastly, there is a close relationship between base and actual salary in practice; base salary accounts for 102.0 percent of actual salary (101.8 and 102.3 for men and women, respectively) on average within institutions and years for which actual salary is observed. Thus, unpaid leave is a key difference between the two measures.

In Table 2, we present descriptive statistics for the full sample used in this study and separately for men and women. There are 50,178 individual university employees across Canada in our sample. On balance, individuals are approximately 49 years old and just over one-quarter of them are women. This masks the fact that, in the 1970s and 1980s, less than 20 percent of

\footnotetext{
${ }^{20}$ Prior to 2008, the department variable is not well-reported. Thus, we proxy for department using a variable for subject taught, which uses the same classification system as the department variable.

${ }^{21}$ In the province of Ontario, salary disclosure is based on tax (calendar) year reporting whereas the salary measure in the data is based on the university's fiscal year reporting. To better align these two measures, we construct two-year averaged salaries between years $t$ and $t-1$ for Ontario and use this variable throughout the analysis. However, the results do not vary significantly using the unadjusted measure.
} 
faculty were women but this has climbed to about 40 percent in recent years, and about 45 percent of new hires during the 2010 s were women. In addition, about 80 percent of faculty hold a $\mathrm{PhD}$ and about 75 percent belong to institutions that are unionized. Interestingly, women are about 5 percentage points more likely to be unionized than men and this is driven by two factors: (1) women are more likely to work at institutions represented by unions or faculty associations; and (2) the proportion of women in the industry has risen over time alongside the gradual increase in unionization from the 1970s to 1990 s.

\section{Empirical Model}

Our empirical model takes advantage of the fact that in the Canadian setting there are three separate sources of variation in pay transparency - provincial, temporal and threshold salary. For example, as discussed above, salary disclosure in Ontario was introduced in 1996 but only individuals whose salaries were above the $\$ 100,000$ threshold were included. ${ }^{22}$

Our baseline definition of treatment takes advantage of all of these sources of variation. Specifically, we define an individual as treated in a given year if, during that year, she or he works in a province where there is a salary disclosure in place and in a department where a faculty member (excluding herself or himself) was revealed by the disclosure policy in the year of the reform. ${ }^{23}$ Our main definition of peer group consists of all faculty in the same Institution and Department. We also report results from another definition based on Institution, Department and Rank. The two definitions of the treatment are conceptually distinct; the former may capture

\footnotetext{
${ }^{22}$ In Ontario, the median salary in 1996 was $\$ 74,950$, thus indicating that many faculty were not necessarily "treated" by the transparency law despite working in Ontario.

${ }^{23}$ According to our definition of treatment, an individual can be untreated if his or her salary is above the threshold but no peers have a salary above the threshold. Our results are virtually unchanged if we instead consider this individual as being treated.
} 
"vertical comparisons" whereas the latter definition is limited to "horizontal comparisons" (see Cullen and Perez-Truglia 2018a).

To formalize our approach, we consider a panel of $i=1, \ldots, N$ individuals in which salary $Y_{i t}$ is observed for $t=1, \ldots, T$ years or for some, a subset thereof. We also observe a binary treatment variable $D_{i t} \in\{0,1\}: D_{i t}=0$ if $i$ has not been treated by year $t$ and $D_{i t}=1$ if $i$ has been treated by year $t$. In our setting, treatment is an absorbing state and the treatment path $\left\{D_{i, t}\right\}_{t=0}^{T}$ is a sequence of zeros and then ones. In this case, the treatment path is uniquely characterized by the time period of the initial treatment, which we denote by $E_{i}=$ $\min \left\{t: D_{i, t}=1\right\}$. This is typically referred to as the "event time" and we denote $K_{i t}=t-E_{i}$ as the "relative time". We let $F_{i}$ be an indicator variable that takes on a value of 1 if individual $i$ is female. We consider the standard dynamic specification:

$$
\log \left(Y_{i t}\right)=\alpha_{i}+\beta_{p t}^{M}+\beta_{p t}^{F}+\sum_{k=-A}^{B} \gamma_{k} 1\left\{K_{i t}=k\right\}+\sum_{k=-A}^{B} \delta_{k} 1\left\{K_{i t}=k\right\} \times F_{i}+\varepsilon_{i t}
$$

where $A \geq 0$ leads of the treatment are included together with $B \geq 0$ terms that capture the short-run effects and a single parameter to capture longer-run effects. Our baseline specification limits the sample to relative years $A=7$ and $B=7$. Our model controls for an individual fixed effect $\left(\alpha_{i}\right)$ and province-by-year-by-gender fixed effects $\left(\beta_{p t}^{M}, \beta_{p t}^{F}\right)(M=$ male, $F=$ female $)$. The latter set of fixed effects control for time-varying, province-specific shocks that might differentially affect male and female salaries and are correlated with the event time.

Our identifying assumption is that there are no shocks correlated with the introduction of transparency laws that differentially affect the salaries of men and women within peer groups (i.e., same department or same rank in the department). The coefficients of interest are the parameters $\left\{\delta_{k}\right\}_{k=-A}^{B}$. These indicate the causal effect of transparency on the gender salary gap in the short-run and long-run, respectively. We can also test for the presence of pre-trends by plotting the $\hat{\delta}_{k}$ for $k<0$ and examining whether $\hat{\delta}_{k}=0$. In all of our event-study figures, we 
normalize $\gamma_{-1}=0$ and $\delta_{-1}=0$ and otherwise estimate the full set of event dummies from -7 to +7 .

Finally, to quantify the magnitude of the effect and to increase precision of our estimates, we adopt the "static" or canonical specification by setting $A=B=0$ :

$$
\log \left(Y_{i t}\right)=\alpha_{i}+\beta_{p t}^{M}+\beta_{p t}^{F}+\gamma_{0+} D_{i t}+\delta_{0+} D_{i t} \times F_{i}+\varepsilon_{i t}
$$

where $\gamma_{0+}$ is the causal effect of transparency on average salaries for male faculty and $\gamma_{0+}+\delta_{0+}$ is the causal effect for female faculty. Compared to the dynamic model, this specification imposes no pre-trends and assumes constant treatment effects for all $k$. The standard errors are clustered at the level of institution, as this is typically the level at which pay scales are determined. Results are robust to clustering by institution and department, which is the level at which treatment is defined in our baseline specification.

\section{Results}

We begin our analysis by providing context for our results through evidence of the gender salary gap among university faculty, and more generally in the Canadian labor market, over our sample period. The gender earnings gap in our sample of faculty is reported in Figure $1 .{ }^{24}$ We present this gap over time both unconditionally and conditional on controls (institution, department, year of birth, number of years since appointed to institution, and years since highest degree obtained). The conditional gender gap was around 6-7 percent at the beginning of the sample and has closed to roughly 2-3 percent in recent years. This is consistent with Warman,

\footnotetext{
${ }^{24}$ While it has become commonplace to measure gender pay disparities with hourly wages in Canada, earnings are the norm in many other countries and we focus on the annual earnings of faculty in our analysis. Using earnings to document gender differences of course may conflate both differences in hours worked (e.g., part-time vs full-time) and differences in hourly wages. This is less of a concern in the present context, as we restrict our sample to full time appointments at the rank of assistant, associate or full professor, and faculty salaries in Canada are typically a fixed amount paid on a 12-month basis.
} 
Woolley and Worswick (2010) who use similar data to document a narrowing in male-female earnings differentials among university faculty between 1990 and 2001.

In Appendix Figure A1 we present evidence of the gender hourly wage ratio for full-time workers in the Canadian labor market from 1997 to $2018 .^{25}$ We report the ratio for all workers and for professional occupations within the educational services sector. The female-male ratio for all workers rises from a low of just over 0.82 to almost 0.89 over the period. The ratio for education workers is more volatile reflecting smaller sample sizes. It begins the period just over 0.88 and rises above 0.90 , except for an abrupt decline in 2018. Throughout almost all of the period, female educational professionals faced a smaller salary gap than their counterparts in the wider labor market.

A potential concern of focusing on pay in the university sector is that salaries may be set according to a statutory formula; for example, they may be entirely determined on the basis of Institution, Department and Rank. To gauge whether there is discretion in pay and scope for transparency laws to impact the gender salary gap, we predict salaries by regressing them on the interaction of institution-department-rank-tenure-year fixed effects, age fixed effects and highest degree obtained fixed effects. If salaries are set in a formulaic way, then there should be very little residual variance between actual salaries and predicted salaries. Figure 2 shows that this is not the case, as we observe substantial residual variation for both men and women. The $R^{2}$ for men is roughly 83 percent and the $R^{2}$ for women is roughly 87 percent. Additionally, the fact that the conditional gender gap is roughly 6-7 percent at the time the first disclosure laws were introduced suggests that there is scope for disclosure to affect the gap.

\footnotetext{
${ }^{25}$ See also Baker and Drolet (2010) and Morisette et al. (2013).
} 
We start our formal analysis by presenting a series of non-parametric event-study plots to visually examine the effects of transparency on the gender salary gap. Next, we turn to regression models to quantify the precise impact.

Figure 3 contains our main event-study figure (equation 1) showing the impact of pay disclosure laws on the gender salary gap. ${ }^{26}$ Panel A splits the sample into male and female faculty members' $\log$ salaries. The dots for male salaries correspond to $\gamma_{k}$ while the squares for female salaries correspond to $\gamma_{k}+\delta_{k}$. Year ' 0 ' is the reform year. All coefficient estimates are expressed relative to the event year -1 (year prior to the reform), which is normalized to 0 .

In panel A, prior to the reform, the time profiles of both the solid round dots (men) and the hollow square dots (women) are fairly congruent, with, at best, modest positive slopes up to the omitted year, indicating that the gender pay gap is approximately static. However, after the reform, the salaries of women increase relative to the omitted time period, while there is a modest, but not statistically significant, initial relative decline in male salaries. The overall impact is a reduction in the gender pay gap due to the disclosure laws, as can be seen in panel B (here we graph estimates of $\delta_{k}$ ), which shows that female salaries increased relative to male salaries.

These figures reveal that there is little movement in the gender gap in the years prior to the reforms, and a clear and noticeable jump around the event year, providing some degree of confidence that we are not merely detecting differential pre-trends. Also, the law's impact on the gender pay gap appears to gradually increase over time. This build up would be consistent with the annual salary setting in most universities, and that it might take some time for information to disseminate and any institutional mechanisms for salary redress to play out. Finally, the figure

\footnotetext{
${ }^{26}$ Treatment is defined based on the year the laws were implemented. Results using year that the salaries were disclosed are very similar and are available upon request.
} 
also shows that salaries tend to be reduced in the long-run $\left(\gamma_{0+}\right.$ is quite low relative to its shortrun effects); however, as we show below, this impact on average wages is not robust.

The regression results (equation 2) are presented in Table 3. We present estimates for male and female salaries separately and for the gender salary gap. Columns (2) and (4) include individual fixed effects and province-by-year-by-gender fixed effects, while columns (1) and (3) omit individual fixed effects. Further, columns (1) and (2) consider the peer group to be institution and department while columns (3) and (4) consider the peer group to be institution, department and rank. ${ }^{27}$

A consistent result across the columns of Table 3 is that the pay transparency laws reduced the gender gap. These estimates are statistically significant at the 1 percent level across all specifications, and robust to the inclusion of individual fixed effects, additional controls and the definition of peer group. ${ }^{28}$ Conditional on the additional controls and the individual and province-year-gender fixed effects, the laws reduced the gender gap by 1.8 to 2 percentage points. Relative to a mean gender gap of 6 to 7 percent at the time of the initial reforms in 1996 (see Figure 1), this effect represents a roughly 30 percent reduction in the gender gap.

We find the effects of the reforms on females' and males' salaries more challenging to precisely estimate. In specifications that include individual fixed effects, when the peer group is defined to be institution and department (column (2)), the estimates for the average salaries of both females and males are statistically insignificant (but indicate some increase in females' salaries, consistent with the evidence in Figure 3), whereas, when we define the peer group on

\footnotetext{
${ }^{27}$ For the peer group specification by institution, department and rank, we assume that individuals compare themselves to peers as follows: (1) assistant professors compare themselves to assistant and associate professors; (2) associate professors compare themselves to all ranks; and (3) full professors compare themselves to associate and full professors.

${ }^{28}$ When the standard errors are clustered by institution and department (rather than by institution), the estimate for Female Salaries in column (2) becomes significant at the 5 percent level.
} 
the basis of institution, department and rank (column (4)), we see a statistically significant decrease in males' salaries. ${ }^{29}$

In the appendix we explore the sensitivity of our estimates to changes in specification and sample. Figure A2 presents estimates of equation (1) corresponding to Figure 3 without the individual fixed effects. Here we also capture any impact of changes in the composition of the sample in and around the reform. There is relatively less stability in the gender salary gap in the years leading up to the reform; however, we again see the relative growth of female salaries post reform, leading to a clear impact of the laws on the gender salary gap.

We also investigate the sensitivity of our results to a wider event time window. Our main estimates are based on a window of $+/-7$ years around the reform. In Figure A3 and Table A1 we extend the window to $+/-14$ years. Note that this requires temporally extending our data back to 1982 to capture 14 years before the first reforms. Among other effects, adding more data to our sample potentially changes the estimates for any regressors not fully interacted with the year effects.

The story in Figure A3 is fairly consistent with the one in Figure 3, though there is clearly less stability in the gender salary gap in the early pre event period, and the post event impact on the gender salary gap is in excess of 2 percentage points. The regression estimates in Table A1 are largely in line with the estimates in Table 3, though there is more consistent evidence that the law had a negative impact on males' salaries.

Finally, where sample sizes permit, we present in Table A2 the effect of the transparency laws by province. For the gender salary gap, only the results for Ontario and Alberta are

\footnotetext{
${ }^{29}$ Note that the latter specification refines the treatment group in a way that changes the levels of the post event salaries of males and females, but not their relative salary positions.
} 
statistically significant, but the majority of the point estimates are consistent with the estimates from the pooled specification.

An important institutional mediator in the Canadian higher education setting are unions, as a large share of faculty are unionized (see Table 2). Unions may play an important role in the response to disclosure, since universities must participate in, and respond to, the formal grievance procedures of unionized workplaces. ${ }^{30}$ In contrast, the request for higher pay in a nonunionized environment is more likely to occur through an informal meeting with a department chair, which may be difficult absent an external competing offer from a peer institution. The availability of a formal grievance procedure might particularly benefit females in an environment in which the majority of chairs and senior faculty are male.

In Table 4, we present estimates of the effect of the treatment separately based on whether faculty were unionized or non-unionized in the year of the reform. The estimates reveal that the primary effect of transparency laws on the gender pay gap is in unionized workplaces. Female salaries increased by roughly 2 percentage points in response to the introduction of a disclosure law. In non-union universities, the change in female salaries is close to zero (column (2)) or declined in tandem with males (column (5)). The union/non-union difference in treatment effect on females' salaries is statistically significant at conventional levels as reported in columns (3) and (6). In line with our baseline results, the laws' estimated impacts on males' or females' salaries by sector display some sensitivity to our identification strategy, whereas the estimated union/non-union difference in the impact on the gender salary gap is more robust. We cannot be certain that this difference by sector is the result of the mechanisms unions provide (discussed above), but this does suggest that the efficacy of the transparency laws turns on something that is different across, rather than common among, union and non-union universities.

\footnotetext{
${ }^{30}$ Another possibility is that unions directly bargain for redress for female faculty, separate from the institutional responses we document in Table A3.
} 
Table 5 considers the extent to which transparency affects the gender pay gap differently across peer groups based on the size of the pay gap within that peer group in years prior to the reform. To estimate this pay gap, we regress log salary on an indicator for being female separately for each peer group and within provinces that enacted a reform. This analysis is implemented at event time -2 to obtain a measure of the pay gap prior to the reforms being implemented. Next, we sort universities on the estimates of the female dummy variable. The departments with the smallest (most negative) coefficients are predicted to have the largest gender salary gaps in the reform year. All peer groups from provinces with no reform or from provinces with reforms but that are not observed at event time -2 , and peer groups for which a gender salary gap cannot be estimated (such as all-male or all-female faculty) are included in the regressions within the control group.

Columns (1) and (3) contain the estimated effects of treatment for peer groups with a small initial gender gap (i.e., less than the median gap), while columns (2) and (4) present the estimates for peer groups with a large initial gender gap (i.e., equal to or greater than the median). In either case, the control group consists of untreated peer groups. The expected difference in the effect of the laws by the initial pay gap is ambiguous. For example, a large initial gap may suggest there is significant scope for transparency to improve pay inequality, leading to the largest effect for this group. However, peer groups with a small initial gap may have greater bargaining power for equal pay, more equal distribution of men and women, greater likelihood of union representation, or other factors that correlate with a large effect of transparency in this case.

The results of this analysis are consistent with the latter hypothesis. The pay gap is reduced by roughly 1.7 percentage points in peer groups with a small initial gap, whereas the effect is virtually zero for those with a large initial gap. This finding is interesting because it suggests that, while transparency reduces gender pay differences in the aggregate, these laws are 
perhaps not sufficient to resolve pay inequality on their own where the problem is most pervasive.

Finally, a number of the universities in our sample undertook campus-wide studies of gender differences in compensation over our sample period. While we do not have direct evidence that these studies were in response to transparency laws, to our knowledge, they have all occurred within provinces after a law has come into effect. The analysis in these studies typically involves the use of regression analysis to estimate the gender pay gap, controlling for factors such as field and experience (years since highest degree and years at institution). In many of these cases, the studies have revealed evidence of a gender gap which has led the university to make a onetime across-the-board adjustment to female faculty salaries. In other cases, a pool of money has been established to grant anomalies to faculty who fall below the regression line. A list of these initiatives, their relevant dates, and the amount and timing of any resulting salary adjustment is presented in Table A3 of the appendix. These studies may be a mechanism by which disclosure affected compensation at the institution level.

\section{Conclusion}

This paper examines the effect of transparency laws on the gender pay gap. While we focus on public sector salaries, the ongoing efforts of governments around the world to increase transparency of wages in the private sector may allow researchers to determine if the effects we document hold in other sectors of the economy.

There are several directions for future research. First, our estimates are informative about the partial equilibrium impacts of transparency. It is possible that transparency laws have spillover effects through broader changes in social norms and, thus, the general equilibrium effects of these laws may be different. Second, transparency laws are complex and vary in their nature. One can distinguish between "active" disclosure whereby salaries are easily accessible online or "passive" 
disclosure in which salaries are only available upon request. These two forms of disclosure may not have the same equilibrium effects on salaries. For example, salaries that are available online may garner significantly more media attention and public pressure for adjustment. Additionally, the lower cost of access means that they are more likely to be used to a greater extent in bargaining with employers.

Finally, the similarity between our results and the results of Bennedsen et al. (2019) is perhaps surprising given the differences in the nature of the transparency laws. Those results show that transparency laws can reduce gender gaps - without identifying individuals. As Cullen and Perez-Truglia (2018b) have shown, non-anonymous information may harm well-being for those who earn less. Indeed these authors have shown that employees like anonymous transparency as in Denmark, but exhibit a distaste for non-anonymous transparency as in Canada and are often willing to pay a significant amount of money to keep their salaries private. This may have implications for policymakers who are considering transparency laws as a way to reduce gender gaps. 


\section{References}

Baker, Michael, and Marie Drolet. (2010). "A New View of the Male/Female Pay Gap," Canadian Public Policy//Analyse de Politiques, 36(4): 429-464.

Bennedsen, Morten, Elena Simintzi, Margarita Tsoutsoura, and Daniel Wolfenzon. (2019). "Do firms respond to gender pay gap transparency?" NBER Working Paper Series, No. 25435.

Boyd, Lara, Creese, Gillian, Rubuliak, Deena, Trowell, Mark, and Claire Young. (2012). "Report of the Gender Pay Equity Recommendation Committee," UBC Faculty Association. Vancouver: University of British Columbia.

Breza, Emily, Kaur, Supreet, and Yogita Shamdasani. (2018). "The Morale Effects of Pay Inequality," Quarterly Journal of Economics, 133: 611-663.

Card, David, Mas, Alexandre, Moretti, Enrico, and Emmanuel Saez. (2012). "Inequality at work: The effect of peer salaries on job satisfaction," American Economic Review, 102: 29813003.

Council of Canadian Academies. (2012). "Strengthening Canada's research capacity: The gender dimension," The Expert Panel on Women in University Research. Ottawa: Council of Canadian Academies.

Cullen, Zoë, and Ricardo Perez-Truglia. (2018a). "How Much Does Your Boss Make? The Effects of Salary Comparisons, ”NBER Working Paper Series, No. 24841.

Cullen, Zoë, and Ricardo Perez-Truglia. (2018b). "The Salary Taboo: Privacy Norms and the Diffusion of Information,” NBER Working Paper Series, No. 25145.

Cullen, Zoë, and Bobak Pakzad-Hurson (2019). "Equilibrium Effects of Pay Transparency in a Simple Labor Market,” Working Paper.

Goldin, Claudia. (2014). "A Grand Gender Convergence: Its Last Chapter," American Economic Review, 104: 1091-1119.

Gomez, Rafael, and Steven Wald. (2010). "When public-sector salaries become public knowledge: Academic salaries and Ontario’s Public Sector Salary Disclosure Act," Canadian Public Administration, 53(1).

Kim, Marlene. (2015). "Pay Secrecy and the Gender Wage Gap in the United States," Industrial Relations, 54(4): 648-667.

Leibbrant, Andreas, and John List. (2014). "Do Women Avoid Salary Negotiations? Evidence from a Large-Scale Natural Field Experiment," Management Science, 61(9).

Mas, Alexandre. (2017). "Does transparency lead to pay compression?" Journal of Political Economy, 125: 1683-1721. 
Morissette, Rene, Garnett, Picot, and Yuqian Lu. (2013). "The evolution of Canadian wages over the last three decades," Analytical Studies Branch Research Paper Series, No. 347. Ottawa: Statistics Canada.

Perez-Truglia, Ricardo. (2019). "The Effects of Income Transparency on Well-Being: Evidence from a Natural Experiment," NBER Working Paper Series, No. 25622.

Trotter, Richard, Zacur, Susan, and Lisa Stickney (2017). "The new age of pay transparency," Business Horizons, 60(4).

Warman, Casey, Woolley, Frances, and Christopher Worswick. (2010). "The evolution of malefemale earnings differentials in Canadian universities, 1970-2001," Canadian Journal of Economics, 43(1). 


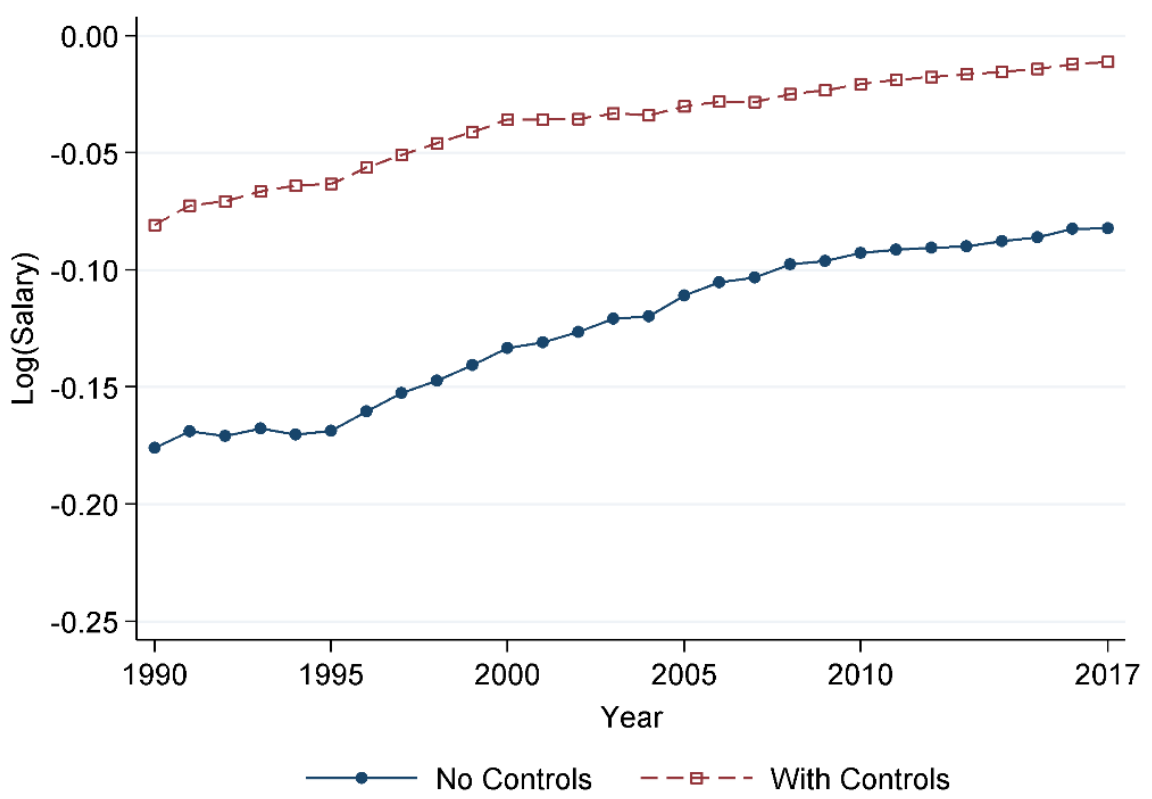

Figure 1: Gender Salary Gap: with versus without Controls by Year

Notes: Results are based on a regression of the log of salary on year fixed effects and their interactions with an indicator for being female. The salary measure used is a base annual rate, which offers a consistent measure of employees' annual earnings both over time and across institutions. To control for outliers, observations with salaries below the 0.5 th percentile or above the 99.5th percentile (in 2017 constant dollars) are dropped. The coefficients of the interaction variables are reported, where 1989 serves as the reference year, after being scaled down by the estimated unconditional gender salary gap from the coefficient for the female indicator. Control variables include institution, department, year of birth, number of years since appointed to institution, and years since highest degree obtained.

Source: Statistics Canada, University and College Academic Staff System, 1989 to 2017. 


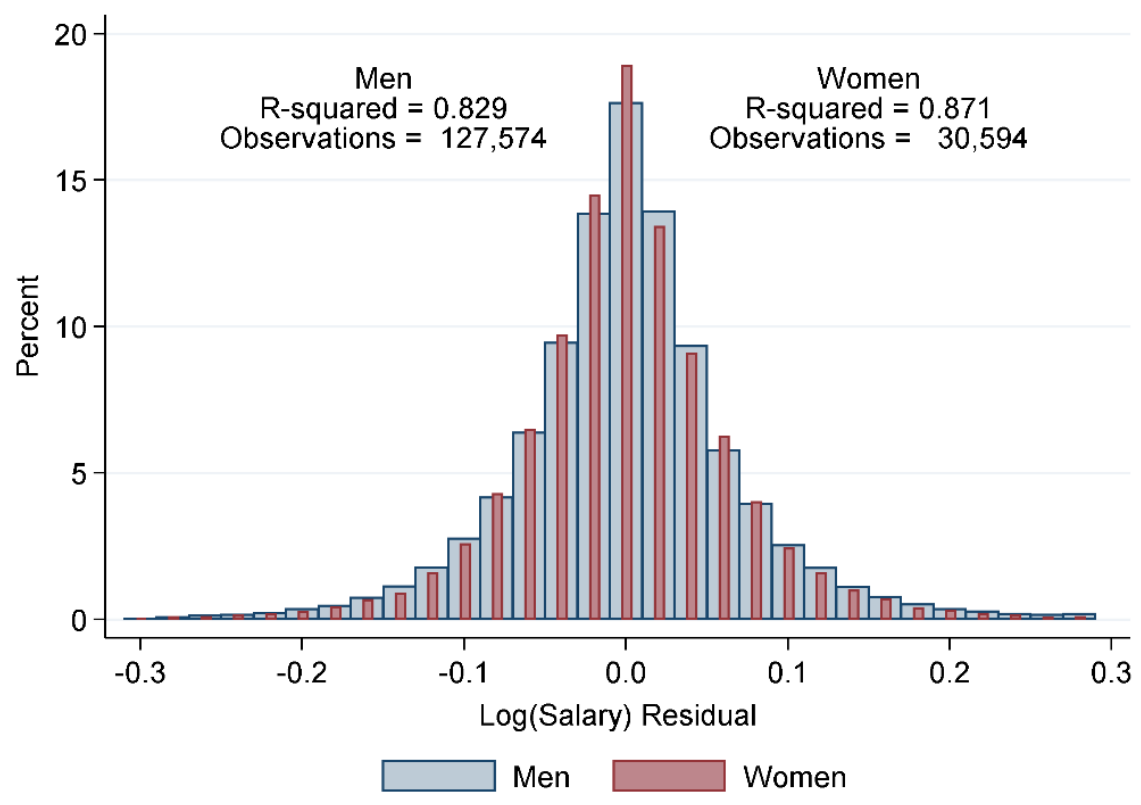

Figure 2: Distribution of the Residuals from Salary Regressions, by Gender

Notes: The distributions are plotted of the residuals from regressions of the log of salary on fixed effects (FEs) for the interaction of institution, department, rank, years since appointed to institution, and year; and FEs for year of birth and highest educational attainment. The salary measure used is a base annual rate, which offers a consistent measure of employees' annual earnings both over time and across institutions. The analysis is carried out separately for men and women using the Stata command 'reghdfe,' which iteratively removes singleton groups. The number of observations reported reflects the number after dropping singleton groups. This analysis uses data for years used in the event study analysis. See the notes in Table 3 for more information. Source: Statistics Canada, University and College Academic Staff System, 1989 to 2017. 


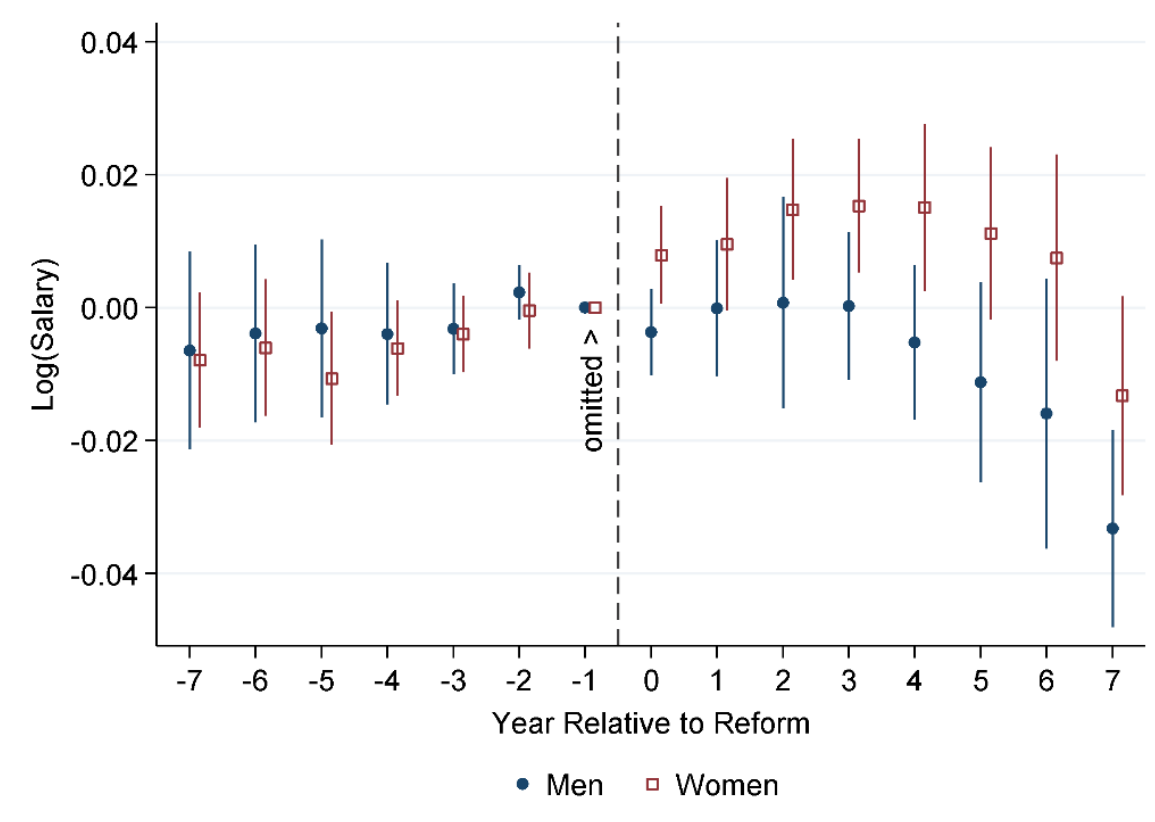

(a) Average Salaries of Men and Women

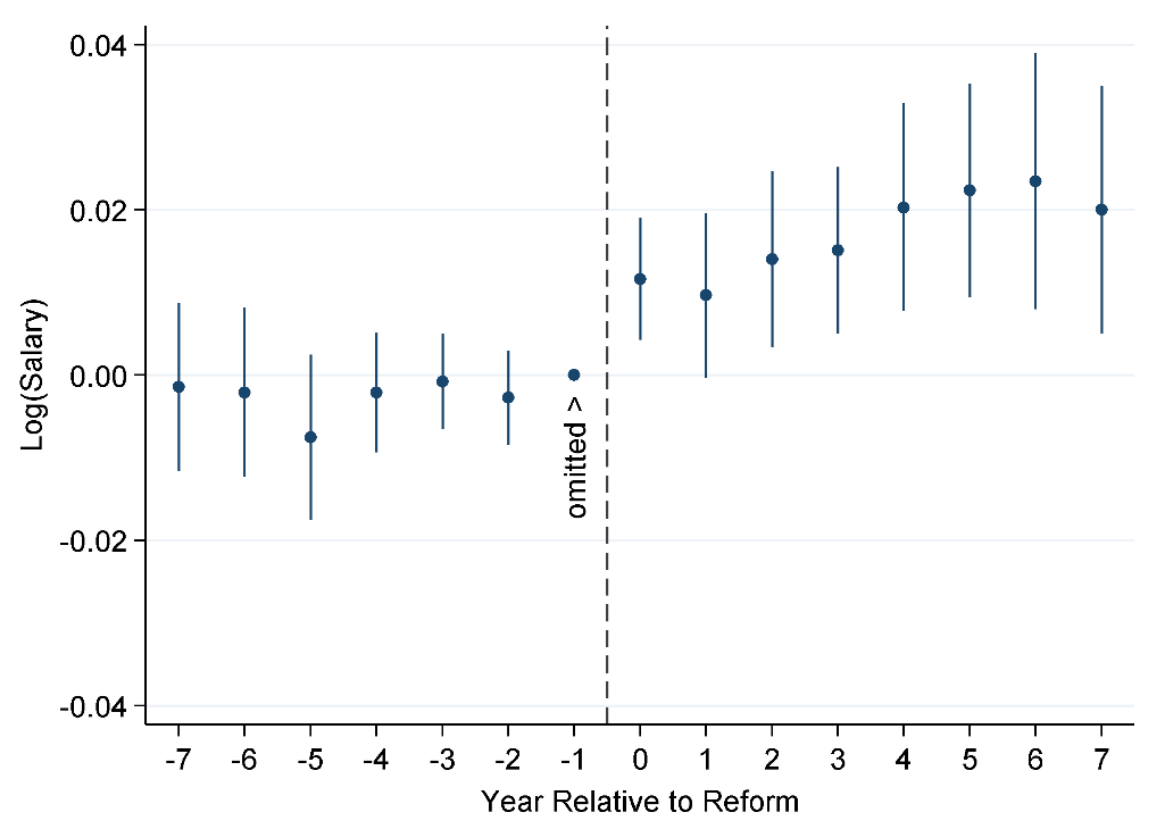

(b) Gender Salary Gap

Figure 3: Event Study of the Effect of Pay Transparency on Average Salaries of Men and Women and Gender Salary Gap, Peer Group Specification by Institution and Department

Notes: The salary measure used is a base annual rate, which offers a consistent measure of employees' annual earnings both over time and across institutions. The analysis controls for fixed effects by individual and province-year-gender. The coefficient for event time -1 is omitted to normalize the gender salary gap to zero in the year prior to the reform. The $95 \%$ confidence intervals shown are based on standard errors clustered by institution. See the notes in Table 3 for more information about the regression specifications.

Source: Statistics Canada, University and College Academic Staff System, 1989 to 2017. 
Table 1: Disclosure Laws

\begin{tabular}{|c|c|c|c|}
\hline & $\begin{array}{c}\text { Year of Implementation } \\
\text { (1) }\end{array}$ & $\begin{array}{c}\text { Disclosure Threshold } \\
\text { (2) }\end{array}$ & $\begin{array}{c}\text { Online Government } \\
\text { Publication } \\
(3)\end{array}$ \\
\hline British Columbia & $1996 / 2002$ & $\$ 50,000 / \$ 75,000$ & No \\
\hline Manitoba & 1996 & $\$ 50,000$ & No \\
\hline Ontario & 1996 & $\$ 100,000$ & Yes \\
\hline Nova Scotia & 2012 & $\$ 100,000$ & Yes \\
\hline Alberta & 2015 & $\$ 125,000$ & Yes \\
\hline Newfoundland and Labrador & 2016 & $\$ 100,000$ & Yes \\
\hline New Brunswick & $\mathrm{N} / \mathrm{A}$ & & \\
\hline Prince Edward Island & $\mathrm{N} / \mathrm{A}$ & & \\
\hline Quebec & N/A & & \\
\hline Saskatchewan & $\mathrm{N} / \mathrm{A}$ & & \\
\hline
\end{tabular}

Notes: In British Columbia, the initial salary reporting threshold of $\$ 50,000$ was amended to $\$ 75,000$ in 2002 . Alberta's threshold is adjusted to the province's consumer price index. There are no pay transparency laws in Prince Edward Island, Quebec, New Brunswick, or Saskatchewan that require universities to disclose non-executive salaries to the province or respond to freedom of information requests for non-anonymized faculty salaries. N/A $=$ Not applicable. 
Table 2: Descriptive Statistics

\begin{tabular}{|c|c|c|c|c|c|c|}
\hline & \multicolumn{2}{|c|}{ Full Sample } & \multicolumn{2}{|c|}{ Men } & \multicolumn{2}{|c|}{ Women } \\
\hline & $\begin{array}{c}\text { Mean } \\
\text { (1) }\end{array}$ & $\begin{array}{c}\text { Standard } \\
\text { Deviation } \\
\text { (2) }\end{array}$ & $\begin{array}{c}\text { Mean } \\
\text { (3) }\end{array}$ & $\begin{array}{c}\text { Standard } \\
\text { Deviation } \\
\text { (4) }\end{array}$ & $\begin{array}{c}\text { Mean } \\
(5)\end{array}$ & $\begin{array}{c}\text { Standard } \\
\text { Deviation } \\
(6)\end{array}$ \\
\hline \multicolumn{7}{|l|}{ Demographics } \\
\hline Age (in Years) & 49.1 & 9.2 & 49.9 & 9.2 & 47.2 & 9.0 \\
\hline Female (Percent) & 27.2 & 44.5 & 0.0 & 0.0 & 100.0 & 0.0 \\
\hline \multicolumn{7}{|l|}{ Highest Degree (Percent) } \\
\hline $\mathrm{PhD}$ & 83.9 & 36.8 & 85.9 & 34.8 & 78.7 & 41.0 \\
\hline Professional & 0.5 & 6.8 & 0.4 & 6.4 & 0.6 & 7.9 \\
\hline Master's & 12.6 & 33.1 & 10.9 & 31.1 & 17.1 & 37.7 \\
\hline Below Master's & 3.1 & 17.3 & 2.9 & 16.7 & 3.6 & 18.6 \\
\hline \multicolumn{7}{|l|}{ Rank (Percent) } \\
\hline Assistant Professor & 20.9 & 40.6 & 16.5 & 37.1 & 32.5 & 46.8 \\
\hline Associate Professor & 39.1 & 48.8 & 37.1 & 48.3 & 44.5 & 49.7 \\
\hline Full Professor & 40.0 & 49.0 & 46.4 & 49.9 & 23.0 & 42.1 \\
\hline \multicolumn{7}{|l|}{ Other Job Traits (Percent) } \\
\hline Unionized & 76.4 & 42.5 & 74.9 & 43.4 & 80.3 & 39.8 \\
\hline Has Responsibilities & 13.0 & 33.7 & 13.6 & 34.3 & 11.5 & 31.9 \\
\hline \multicolumn{7}{|l|}{ Compensation } \\
\hline \multicolumn{7}{|l|}{ Salary (Dollars) } \\
\hline Full Sample & 115,450 & 25,950 & 118,900 & 25,800 & 106,250 & 24,050 \\
\hline Assistant Professor & 87,750 & 16,450 & 88,500 & 17,000 & 86,800 & 15,550 \\
\hline Associate Professor & 109,950 & 17,200 & 111,050 & 17,250 & 107,500 & 16,950 \\
\hline Full Professor & 135,300 & 20,700 & 136,050 & 20,550 & 131,200 & 21,250 \\
\hline \multicolumn{7}{|l|}{ Salary Growth (Percent) } \\
\hline Full Sample & 2.5 & 5.0 & 2.3 & 4.9 & 3.1 & 5.3 \\
\hline Assistant Professor & 3.4 & 4.7 & 3.4 & 4.7 & 3.5 & 4.8 \\
\hline Associate Professor & 2.7 & 5.0 & 2.6 & 4.9 & 3.1 & 5.1 \\
\hline Full Professor & 2.0 & 5.1 & 1.9 & 4.9 & 2.7 & 6.0 \\
\hline Number of individuals & 50,178 & & 35,016 & & 15,162 & \\
\hline Number of observations & 392,772 & & 285,908 & & 106,864 & \\
\hline
\end{tabular}

Notes: The salary measure used is a base annual rate, which offers a consistent measure of employees' annual earnings both over time and across institutions. To control for outliers, observations with salaries below the 0.5 th percentile or above the 99.5 th percentile (in 2017 constant dollars) are dropped. The currency values are rounded to the nearest $\$ 50$ and are expressed in 2017 constant dollars. The descriptive statistics refer to data for years used in the event study analysis and are computed using all years. More precisely, the reported averages are full-sample averages calculated over all observations. See the notes in Table 3 for more information.

Source: Statistics Canada, University and College Academic Staff System, 1989 to 2017. 
Table 3: Effect of Pay Transparency on Average Salaries and the Gender Salary Gap

\begin{tabular}{|c|c|c|c|c|}
\hline & \multicolumn{4}{|c|}{ Peer Group Specification } \\
\hline & \multicolumn{2}{|c|}{ Institution and Department } & \multicolumn{2}{|c|}{ Institution, Department and Rank } \\
\hline & $(1)$ & $(2)$ & $(3)$ & $(4)$ \\
\hline \multirow[t]{2}{*}{ Male Salaries } & $0.017 * *$ & -0.004 & $0.034 * * *$ & $-0.017 * * *$ \\
\hline & $(0.007)$ & $(0.007)$ & $(0.007)$ & $(0.006)$ \\
\hline \multirow[t]{2}{*}{ Female Salaries } & $0.032 * * *$ & 0.014 & $0.052 * * *$ & 0.003 \\
\hline & $(0.006)$ & $(0.010)$ & $(0.007)$ & $(0.010)$ \\
\hline \multirow[t]{2}{*}{ Gender Salary Gap } & $0.015 * * *$ & $0.018 * * *$ & $0.019 * * *$ & $0.020 * * *$ \\
\hline & $(0.005)$ & $(0.006)$ & $(0.005)$ & $(0.006)$ \\
\hline R-squared & 0.644 & 0.939 & 0.646 & 0.939 \\
\hline Number of Observations & 377,773 & 372,073 & 377,773 & 372,073 \\
\hline Number of Clusters & 52 & 51 & 52 & 51 \\
\hline Institution FEs & $\checkmark$ & & $\checkmark$ & \\
\hline Department FEs & $\checkmark$ & & $\checkmark$ & \\
\hline Individual FEs & & $\checkmark$ & & $\checkmark$ \\
\hline Province-Year-Gender FEs & $\checkmark$ & $\checkmark$ & $\checkmark$ & $\checkmark$ \\
\hline Additional Controls & $\checkmark$ & $\checkmark$ & $\checkmark$ & $\checkmark$ \\
\hline
\end{tabular}

Notes: The estimates for Male Salaries and the Gender Salary Gap correspond to the coefficient estimates for the treatment effect $\left(\gamma_{0+}\right)$ and its interaction with the female indicator $\left(\delta_{0+}\right)$, respectively, from equation (1) described in the main text. The estimates for Female Salaries are computed as the sum of these two effects $\left(\gamma_{0_{+}}+\delta_{0_{+}}\right)$. The salary measure used is a base annual rate, which offers a consistent measure of employees' annual earnings both over time and across institutions. Additional controls include an indicator for having senior administrative responsibilities in all regressions, as well as experience measures for the number of years since appointed to institution and years since highest degree obtained in the regressions without individual fixed effects (FEs). When individual and year FEs are both included, experience is collinear notwithstanding cases in which individuals take unpaid time off or obtain a higher degree after being appointed to the institution. Individual FEs nest the institution and department FEs, so that institution and department FEs need not be explicitly included in the regressions when individual FEs are included. Responsibilities are defined as appointments to senior administrative roles, including: dean; assistant, associate, or vice dean; director whose responsibility and salary is equivalent to dean; department head or coordinator; and chairperson. Models are estimated using the Stata command 'reghdfe,' which calculates degrees of freedom lost due to FEs and iteratively removes singleton groups to avoid biasing standard errors. For the peer group specification by institution, department and rank, individuals compare themselves to peers as follows: (1) assistant professors compare themselves to assistant and associate professors; (2) associate professors compare themselves to all ranks; and (3) full professors compare themselves to associate and full professors. In all regressions, the analysis includes data for years used in the event study analysis, namely: 1989 to 2003 for British Columbia, Manitoba and Ontario; 2005 to 2017 for Nova Scotia; 2008 to 2017 for Alberta; 2009 to 2017 for Newfoundland and Labrador; and 1989 to 2017 for New Brunswick, Prince Edward Island, Quebec and Saskatchewan. The full time period is used for these latter provinces because no reform occurred, so it is not possible to center the data on a 7-year interval around the reform. Standard errors (in parentheses) are clustered by institution. $\checkmark$ denotes included in the regression. $* * *, * *$, and $*$ denote significant at the 1,5 and 10 percent levels, respectively.

Source: Statistics Canada, University and College Academic Staff System, 1989 to 2017. 
Table 4: Effects of Pay Transparency by Union Status

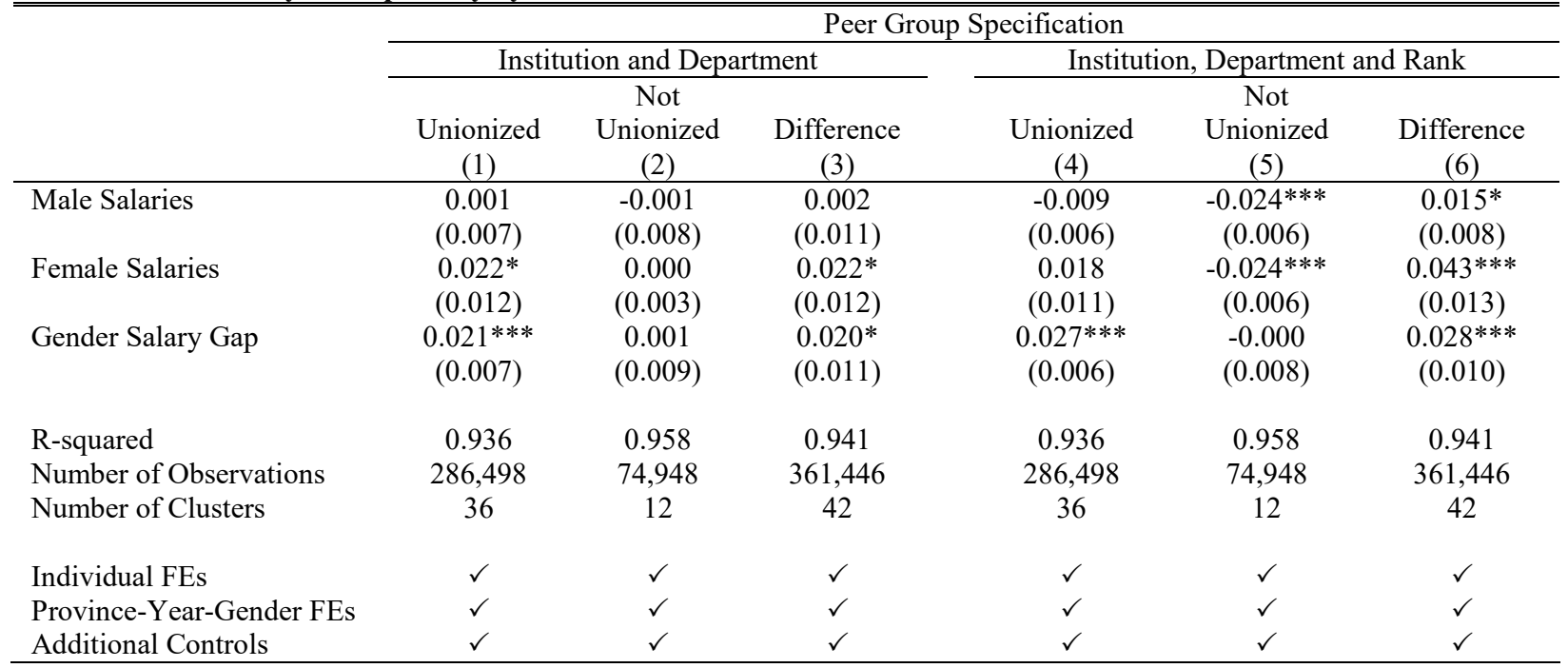

Notes: The estimates for Male Salaries and the Gender Salary Gap correspond to the coefficient estimates for the treatment effect $\left(\gamma_{0+}\right)$ and its interaction with the female indicator $\left(\delta_{0+}\right)$, respectively, from the econometric specification described in text. The estimates for Female Salaries are computed as the sum of these two effects $\left(\gamma_{0+}+\delta_{0+}\right)$. The salary measure used is a base annual rate, which offers a consistent measure of employees' annual earnings both over time and across institutions. Union status is assigned to each institution on a yearly basis; most institutions that switched union status did so during the 1970s and 1980s before the time period used in this analysis. Standard errors (in parentheses) are clustered by institution. See the notes in Table 3 for more information about the regression specifications. $\checkmark$ denotes included in the regression. $* * *, * *$, and $*$ denote significant at the 1,5 and 10 percent levels, respectively.

Source: Statistics Canada, University and College Academic Staff System, 1989 to 2017. 
Table 5: Effects of Pay Transparency by Size of the Initial Gender Salary Gap

\begin{tabular}{|c|c|c|c|c|}
\hline & \multicolumn{4}{|c|}{ Peer Group Specification } \\
\hline & \multicolumn{2}{|c|}{ Institution and Department } & \multicolumn{2}{|c|}{ Institution, Department and Rank } \\
\hline & $\begin{array}{c}\text { Small Initial } \\
\text { Gender Salary } \\
\text { Gap } \\
\text { (1) }\end{array}$ & $\begin{array}{c}\text { Large Initial } \\
\text { Gender Salary } \\
\text { Gap } \\
(2)\end{array}$ & $\begin{array}{c}\text { Small Initial } \\
\text { Gender Salary Gap } \\
(3)\end{array}$ & $\begin{array}{c}\text { Large Initial } \\
\text { Gender Salary Gap } \\
(4)\end{array}$ \\
\hline Male Salaries & $\begin{array}{l}-0.003 \\
(0.007)\end{array}$ & $\begin{array}{l}-0.004 \\
(0.007)\end{array}$ & $\begin{array}{l}-0.006 \\
(0.007)\end{array}$ & $\begin{array}{c}-0.015^{* * *} \\
(0.005)\end{array}$ \\
\hline Female Salaries & $\begin{array}{c}0.014 \\
(0.011)\end{array}$ & $\begin{array}{l}-0.004 \\
(0.010)\end{array}$ & $\begin{array}{c}0.009 \\
(0.010)\end{array}$ & $\begin{array}{l}-0.014 \\
(0.009)\end{array}$ \\
\hline Gender Salary Gap & $\begin{array}{c}0.016^{* *} \\
(0.006)\end{array}$ & $\begin{array}{c}0.000 \\
(0.007)\end{array}$ & $\begin{array}{c}0.015^{* *} \\
(0.007)\end{array}$ & $\begin{array}{c}0.002 \\
(0.007)\end{array}$ \\
\hline R-squared & 0.930 & 0.934 & 0.932 & 0.935 \\
\hline Number of Observations & 244,112 & 286,385 & 252,601 & 281,527 \\
\hline Number of Clusters & 51 & 51 & 51 & 51 \\
\hline Individual FEs & $\checkmark$ & $\checkmark$ & $\checkmark$ & $\checkmark$ \\
\hline Province-Year-Gender FEs & $\checkmark$ & $\checkmark$ & $\checkmark$ & $\checkmark$ \\
\hline Additional Controls & $\checkmark$ & $\checkmark$ & $\checkmark$ & $\checkmark$ \\
\hline
\end{tabular}

Notes: The estimates for Male Salaries and the Gender Salary Gap correspond to the coefficient estimates for the treatment effect $\left(\gamma_{0+}\right)$ and its interaction with the female indicator $\left(\delta_{0+}\right)$, respectively, from the econometric specification described in text. The estimates for Female Salaries are computed as the sum of these two effects $\left(\gamma_{0+}+\delta_{0+}\right)$. The salary measure used is a base annual rate, which offers a consistent measure of employees' annual earnings both over time and across institutions. The initial gender salary gap corresponds to the gap that prevailed within the peer group two years prior to the reform in that province. This gap is estimated as follows. Regress the log of salary on an indicator for being female, separately for each peer group and within provinces that enacted a reform and at event time -2 . Then, obtain the coefficient estimates for the female indicator and sort these estimates. The departments with the smallest (most negative) coefficients are predicted to have the largest gender salary gaps in the reform year. All peer groups from provinces with no reform, from provinces with reforms but that are not observed at event time -2 , or for which a gender salary gap cannot be estimated (such as all-male or all-female faculty) are included in the regressions within the control group. Columns 1 and 3 exclude peer groups with large initial gender salary gaps and columns 2 and 4 exclude peer groups with small initial gender salary gaps. Standard errors (in parentheses) are clustered by institution. See the notes in Table 3 for more information about the regression specifications. $\checkmark$ denotes included in the regression. ***, **, and * denote significant at the 1,5 and 10 percent levels, respectively.

Source: Statistics Canada, University and College Academic Staff System, 1989 to 2017. 


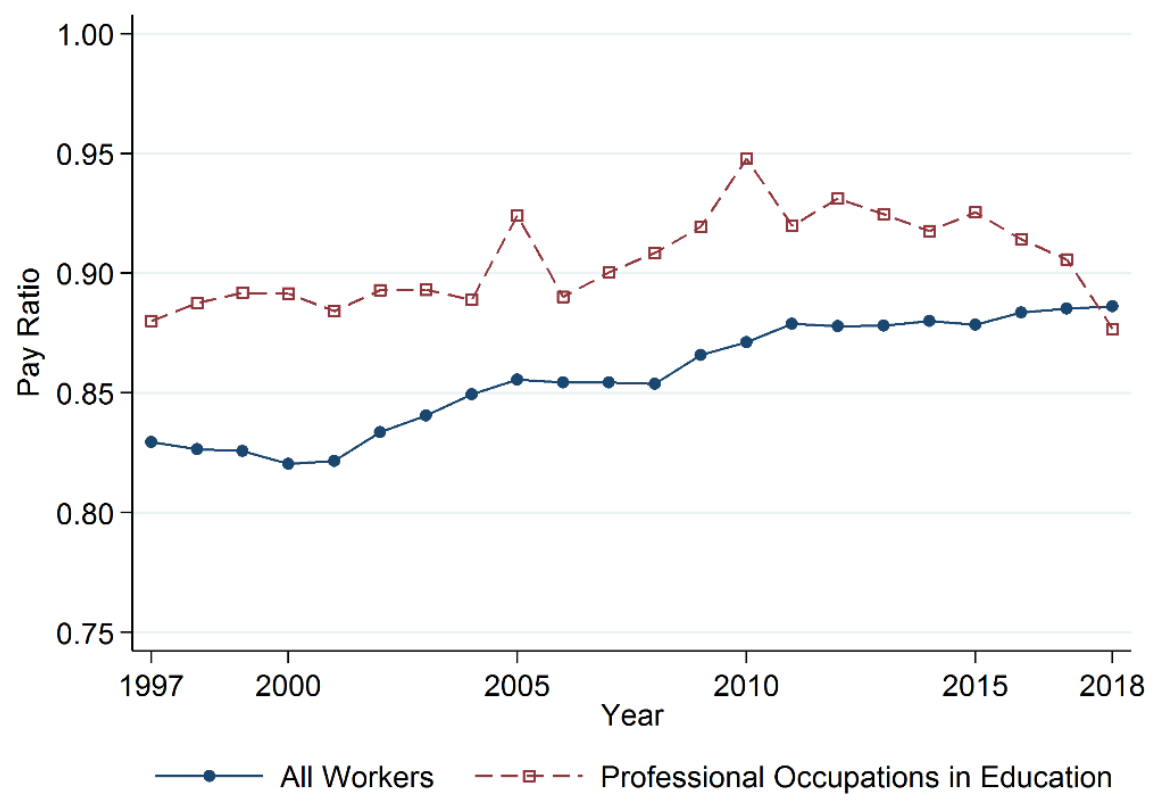

Figure A1: Female-to-Male Hourly Wage Ratio for Full-Time Workers in the Canadian Labor Market by Year

Notes: The reported statistics are the ratios of average female hourly wages to average male hourly wages among full-time workers, in the indicated industries.

Source: Statistics Canada, authors' compilation from table 14-10-0307-01, 1997 to 2018. 


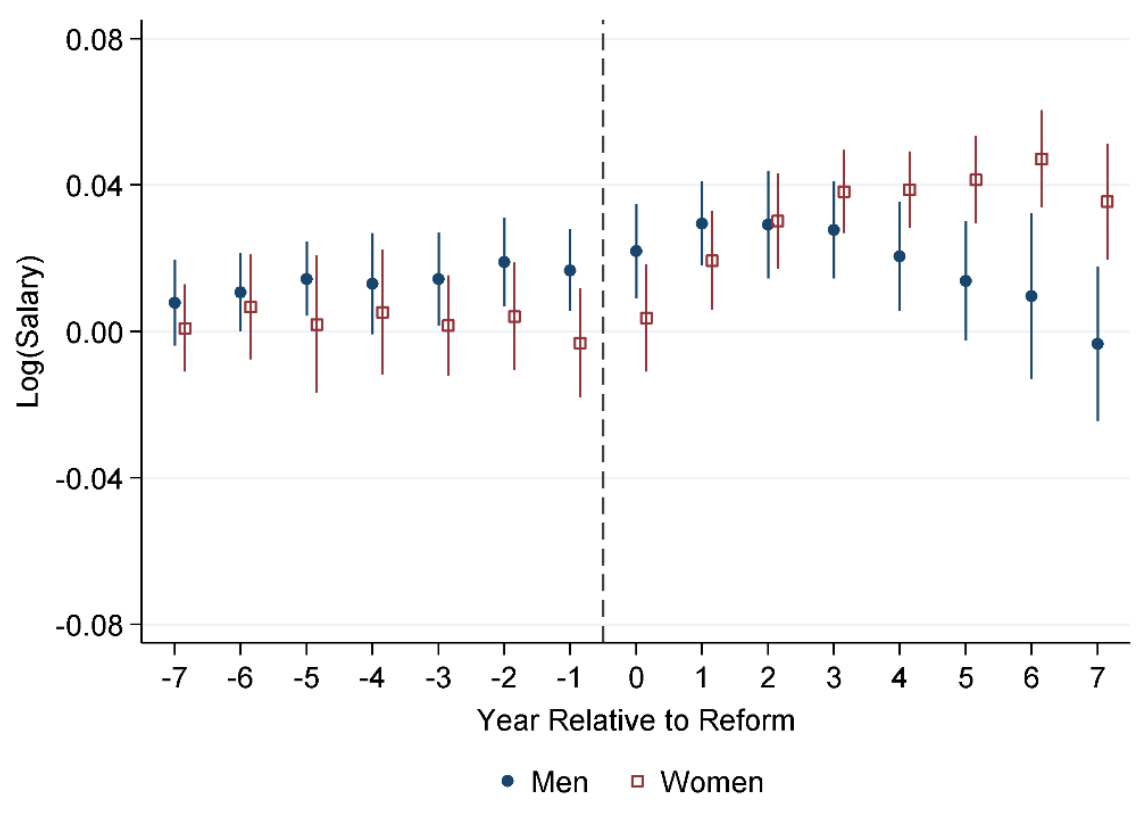

(a) Average Salaries of Men and Women

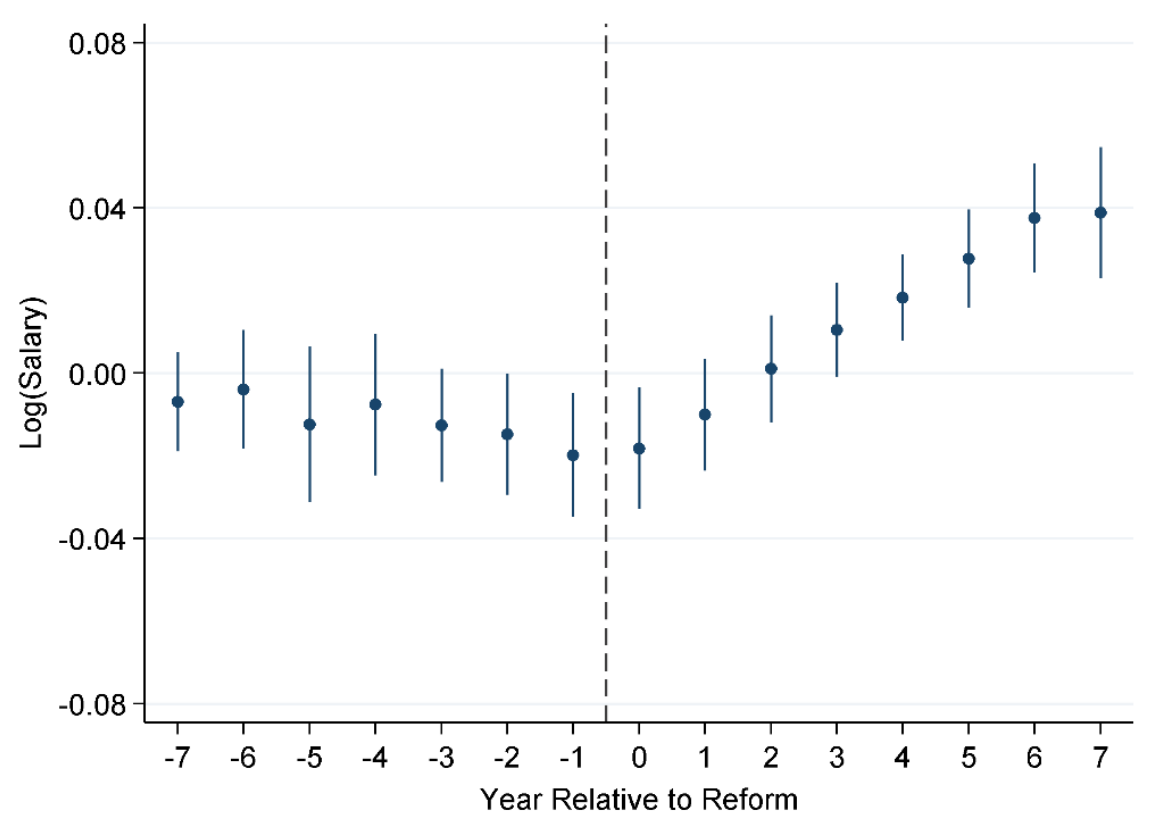

(b) Gender Salary Gap

Figure A2: Event Study without Individual Fixed Effects

Notes: This analysis replicates Figure 3 except that individual fixed effects (FEs) are omitted, whereas additional controls are included for the number of years since appointed to institution, years since highest degree obtained, and an indicator for having senior administrative responsibilities. The institution and department FEs are also included. In this specification with provinceyear-gender FEs but omitting the individual FEs, the event-time coefficients show estimates of the average salary of treated peer groups within the treated provinces around the time of the reforms, expressed relative to peer groups in treated provinces but for which no peer salary was above the threshold for disclosure. As such, normalizing an event-time coefficient to zero is not necessary because they are all well-identified from the within-province heterogeneity in the treatment. These results correspond to the regression estimates in column (1) of Table 3. See the notes in Figure 3 for more information.

Source: Statistics Canada, University and College Academic Staff System, 1989 to 2017. 


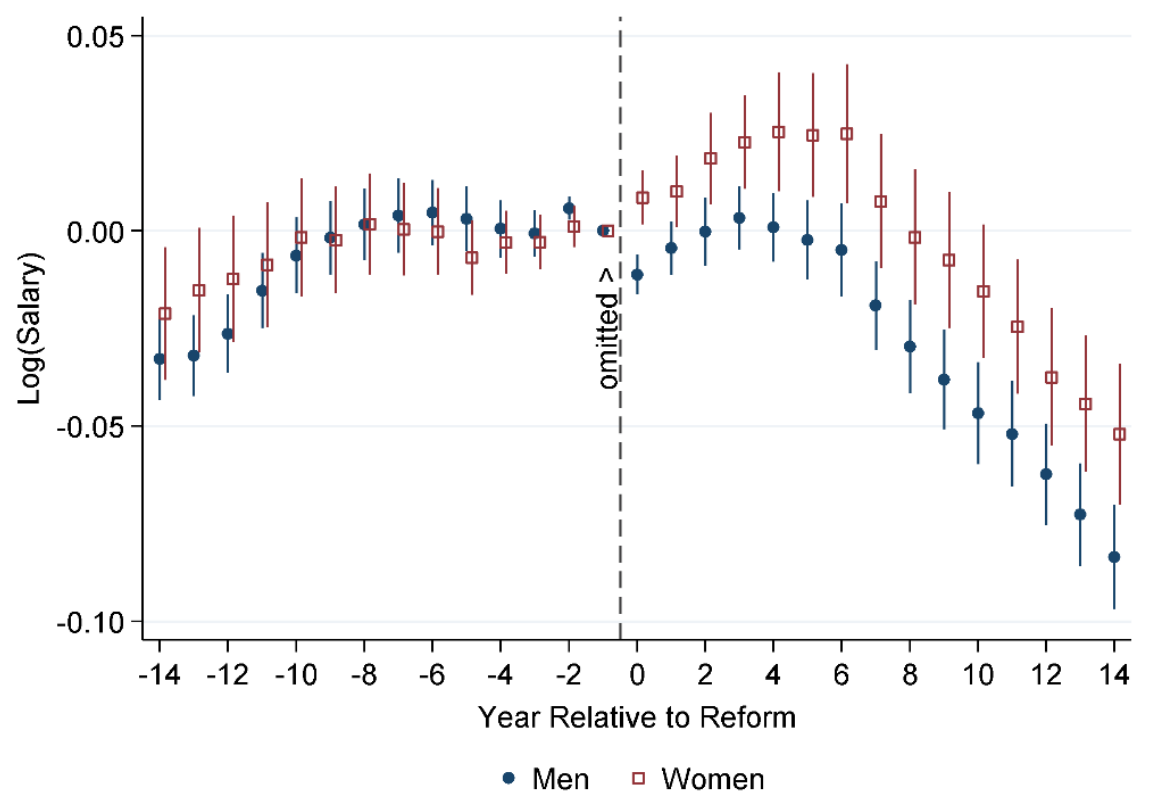

(a) Average Salaries of Men and Women

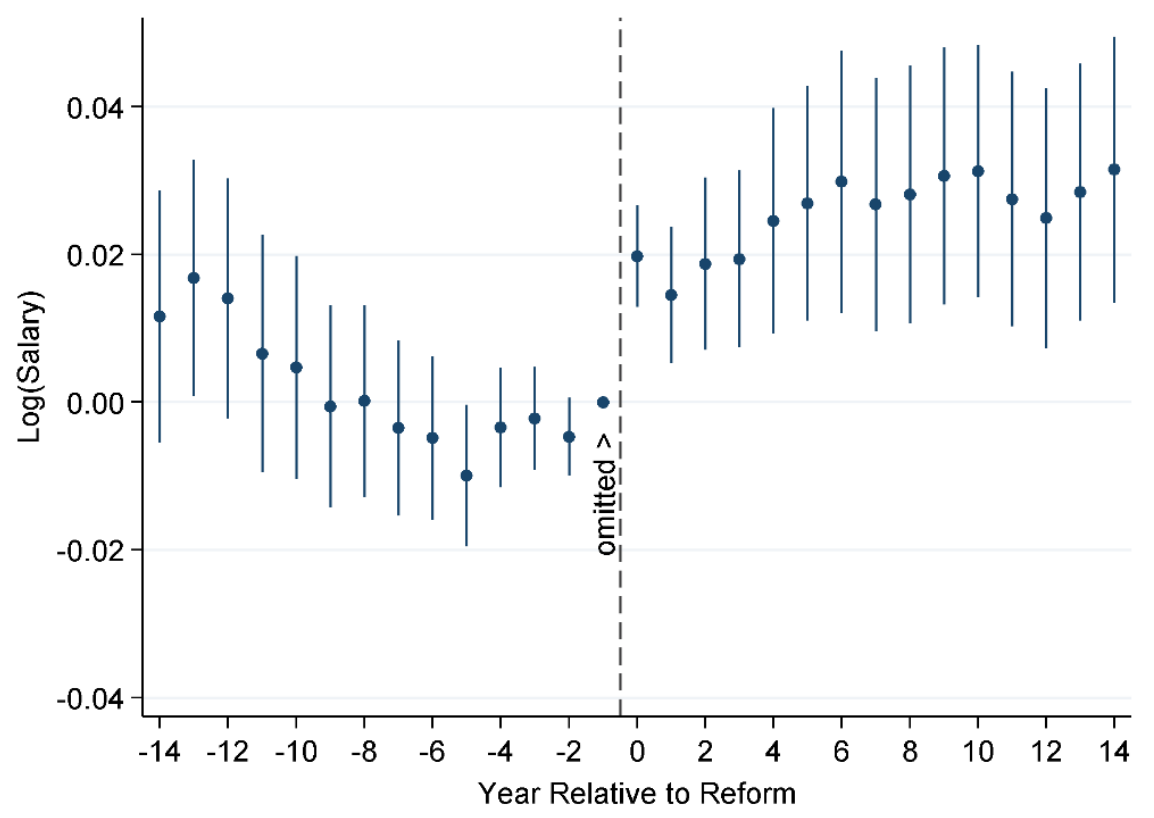

(b) Gender Salary Gap

Figure A3: Event Study using a Wide Event-Time Window

Notes: This analysis replicates Figure 3 except that a wide event-time window is used, spanning 14 years on either side of the reform. Standard errors are clustered by institution and department in this case, due to the larger number of coefficients being estimated relative to the number of clusters. See the notes in Figure 3 for more information. Source: Statistics Canada, University and College Academic Staff System, 1982 to 2017. 
Table A1: Effect of Pay Transparency using a Wide Event-Time Window

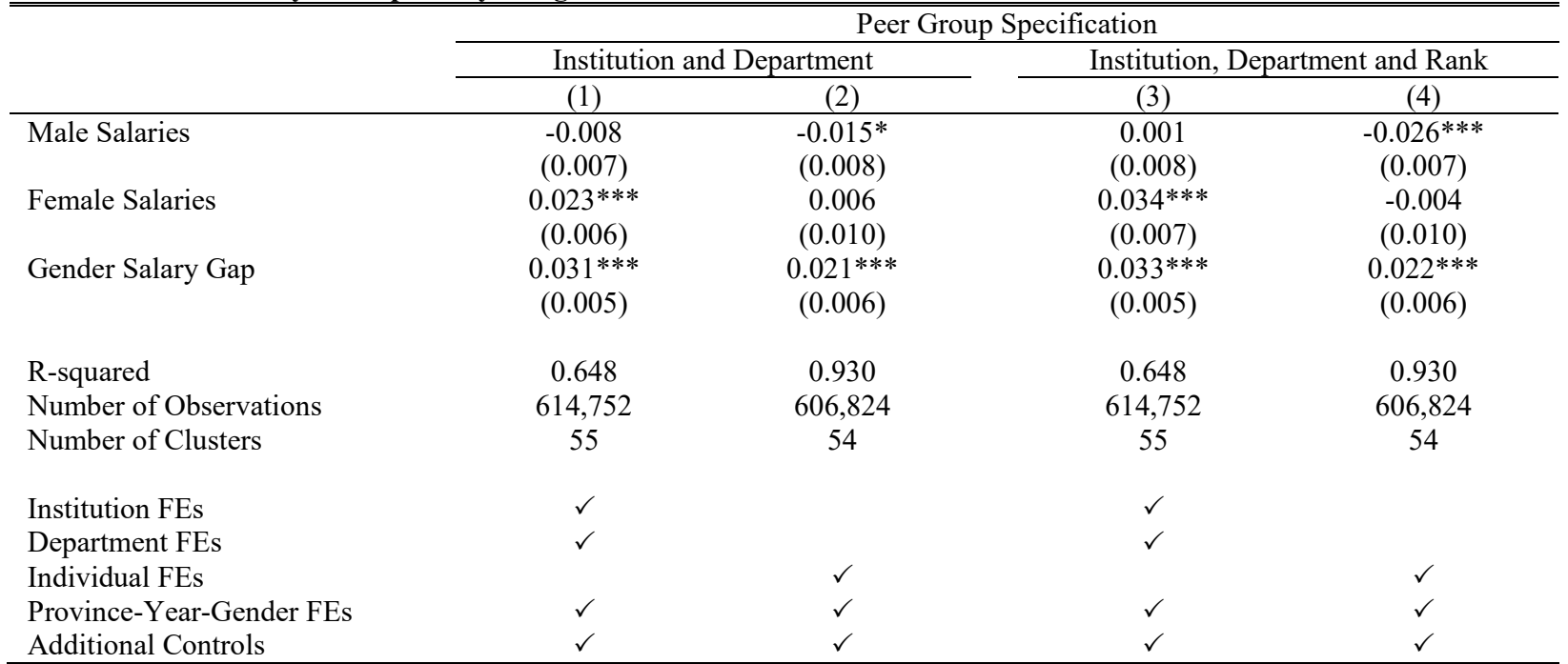

Notes: This analysis replicates Table 3 except that a wide event-time window is used, spanning 14 years on either side of the reform. See the notes in Table 3 for more information. Standard errors (in parentheses) are clustered by institution. $\checkmark$ denotes included in the regression. $* * *, * *$, and $*$ denote significant at the 1,5 and 10 percent levels, respectively.

Source: Statistics Canada, University and College Academic Staff System, 1982 to 2017. 


\section{Table A2: Heterogeneous Effects of Pay Transparency by Province}

\begin{tabular}{|c|c|c|c|c|c|c|c|c|}
\hline & \multicolumn{8}{|c|}{ Peer Group Specification } \\
\hline & \multicolumn{4}{|c|}{ Institution and Department } & \multicolumn{4}{|c|}{ Institution, Department and Rank } \\
\hline & $\begin{array}{l}\text { Ontario } \\
\text { (1) }\end{array}$ & $\begin{array}{l}\text { British } \\
\text { Columbia } \\
\text { (2) }\end{array}$ & $\begin{array}{c}\text { Nova Scotia } \\
\text { (3) }\end{array}$ & $\begin{array}{l}\text { Alberta } \\
\text { (4) }\end{array}$ & $\begin{array}{c}\text { Ontario } \\
\text { (5) }\end{array}$ & $\begin{array}{l}\text { British } \\
\text { Columbia } \\
\text { (6) }\end{array}$ & $\begin{array}{c}\text { Nova Scotia } \\
\text { (7) }\end{array}$ & $\begin{array}{c}\text { Alberta } \\
(8)\end{array}$ \\
\hline \multirow[t]{2}{*}{ Male Salaries } & -0.004 & -0.010 & 0.027 & $-0.033 * * *$ & $-0.017 * * *$ & -0.010 & 0.006 & $-0.034 * * *$ \\
\hline & $(0.007)$ & $(0.027)$ & $(0.023)$ & $(0.003)$ & $(0.006)$ & $(0.027)$ & $(0.008)$ & $(0.004)$ \\
\hline \multirow[t]{2}{*}{ Female Salaries } & 0.015 & $0.030^{*}$ & 0.016 & -0.015 & 0.003 & $0.030^{*}$ & 0.027 & -0.018 \\
\hline & $(0.011)$ & $(0.017)$ & $(0.022)$ & $(0.011)$ & $(0.011)$ & $(0.017)$ & $(0.029)$ & $(0.011)$ \\
\hline \multirow[t]{2}{*}{ Gender Salary Gap } & $0.019 * * *$ & 0.040 & -0.011 & $0.018^{*}$ & $0.020 * * *$ & 0.040 & 0.021 & $0.017^{*}$ \\
\hline & $(0.007)$ & $(0.040)$ & $(0.045)$ & $(0.009)$ & $(0.007)$ & $(0.040)$ & $(0.037)$ & $(0.008)$ \\
\hline R-squared & 0.952 & 0.942 & 0.955 & 0.967 & 0.952 & 0.942 & 0.955 & 0.967 \\
\hline Number of Observations & 248,671 & 143,490 & 87,443 & 72,962 & 248,671 & 143,490 & 87,443 & 72,962 \\
\hline Number of Clusters & 46 & 29 & 23 & 23 & 46 & 29 & 23 & 23 \\
\hline Number of Treated Institutions & 16 & 3 & 3 & 3 & 16 & 3 & 3 & 3 \\
\hline Number of Treated Peer Groups & 156 & 66 & 40 & 56 & 327 & 194 & 104 & 148 \\
\hline Individual FEs & $\checkmark$ & $\checkmark$ & $\checkmark$ & $\checkmark$ & $\checkmark$ & $\checkmark$ & $\checkmark$ & $\checkmark$ \\
\hline Province-Year-Gender FEs & $\checkmark$ & $\checkmark$ & $\checkmark$ & $\checkmark$ & $\checkmark$ & $\checkmark$ & $\checkmark$ & $\checkmark$ \\
\hline Additional Controls & $\checkmark$ & $\checkmark$ & $\checkmark$ & $\checkmark$ & $\checkmark$ & $\checkmark$ & $\checkmark$ & $\checkmark$ \\
\hline
\end{tabular}

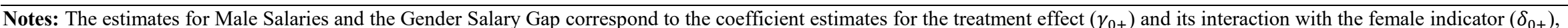

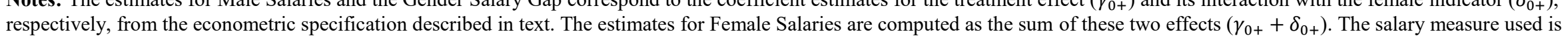

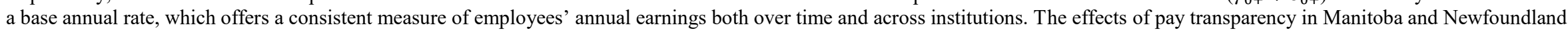

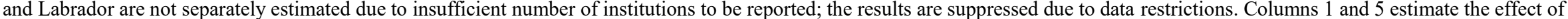
pay transparency in Ontario, introduced in 1996, using data from all provinces except Manitoba and British Columbia from 1989 to 2003 . The two provinces are excluded because they also introduced pay transparency in 1996. All other provinces either did not adopt pay transparency or did so after 2003. Similarly, columns 2 and 6 estimate the effects of pay

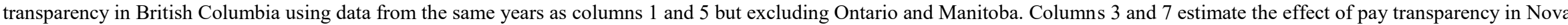
Scotia, introduced in 2012, using data from 2005 to 2017 and excluding Ontario, Manitoba, British Columbia (where reforms had already occurred), Alberta and Newfoundland and

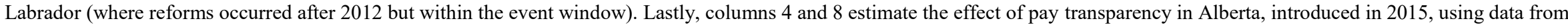

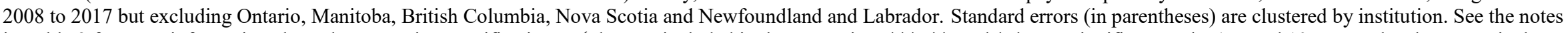
in Table 3 for more information about the regression specifications. $\checkmark$ denotes included in the regression. $* * *, * *$, and $*$ denote significant at the 1,5 and 10 percent levels, respectively.

Source: Statistics Canada, University and College Academic Staff System, 1989 to 2017. 
Table A3: Known Examples of Institutional Studies into Gender Pay Equity and Women's Pay Adjustments Year(s) of Study

\begin{tabular}{lc}
\hline Western Ontario University & 2005,2009 \\
University of British Columbia & 2010 \\
University of Victoria & 2014 \\
McMaster University & 2015 \\
Simon Fraser University & 2015 \\
University of Waterloo & 2016 \\
Wilfrid Laurier University & 2017 \\
Guelph University & 2018 \\
University of Toronto & 2019 \\
\hline
\end{tabular}
Date of Pay Adjustment Size of Adjustment

Notes: At Simon Fraser University, a fund of $\$ 4.0$ million was established to provide some retroactive compensation. The adjustment at University of British Columbia was retroactive to July 1, 2010. At Western Ontario University, a 'below-the-line' rather than across-the-board or group award was implemented; the salary adjustments were administered by the university's salary anomaly committee. The stated adjustment at Wilfred Laurier University was for associate professors, and for full professors it was 3.9\%; those adjustments were retroactive to July 1, 2016. 